Proceedings of the 34rd Meeting of the Association of Embryo Transfer in Europe (AETE); Nantes, France, September 7th and 8th, 2018.

\title{
Directions and applications of CRISPR technology in livestock research
}

\author{
IsmaeI Lamas-Toranzo, Priscila Ramos-Ibeas, Eva Pericuesta, Pablo Bermejo-Álvarez ${ }^{1}$
}

Department Reproducción Animal, INIA, 28040 Madrid, Spain.

\begin{abstract}
The ablation (KO) or targeted insertion (KI) of specific genes or sequences has been essential to test their roles on a particular biological process. Unfortunately, such genome modifications have been largely limited to the mouse model, as the only way to achieve targeted mutagenesis in other mammals required from somatic cell nuclear transfer, a time- and resource-consuming technique. This difficulty has left research in livestock species largely devoided of $\mathrm{KO}$ and targeted KI models, crucial tools to uncover the molecular roots of any physiological or pathological process. Luckily, the eruption of site-specific endonucleases, and particularly CRISPR technology, has empowered farm animal scientists to consider projects that could not develop before. In this sense, the availability of genome modification in livestock species is meant to change the way research is performed on many fields, switching from descriptive and correlational approaches to experimental research. In this review we will provide some guidance about how the genome can be edited by CRISPR and the possible strategies to achieve $\mathrm{KO}$ or $\mathrm{KI}$, paying special attention to an initially overlooked phenomenon: mosaicism. Mosaicism is produced when the zygote's genome edition occurs after its DNA has replicated, and is characterized by the presence of more than two alleles in the same individual, an undesirable outcome when attempting direct KO generation. Finally, the possible applications on different fields of livestock research, such as reproduction or infectious diseases are discussed.
\end{abstract}

\section{Introduction}

Genome modification has been crucial to understand the molecular root of physiological or pathological processes. The ablation (knock-out, KO) or insertion (knock-in, KI) of specific genes or sequences have allowed to unequivocally assess the role of a specific gene product on a particular process, to assess the spatial and temporal expression of a gene or to modify its expression pattern, among other applications. $\mathrm{KO}$ generation requires targeted mutagenesis (i.e., the modification of the genome at a specific locus), and targeted KI (i.e., the insertion of a sequence at a specific locus) is also preferred to random KI. Most experiments involving $\mathrm{KO}$ or $\mathrm{KI}$ models have been carried out in the only mammalian species where targeted genome modification was easily achievable: the laboratory mouse. In this sense, although non-targeted mutagenesis, achieved by different means such as such as pronuclear injection (Hammer et al., 1985), transduction (Chan et al., 1998) or mediated by intracytoplasmic sperm injection (Shemesh et al., 2000) have been applied to farm animals, the only available method to achieve targeted mutagenesis, homologous recombination, was difficult to apply to livestock species.

Homologous recombination (HR) is a genome modification technique based on an homonymous DNA repair mechanism that can be directed to insert a given sequence in a specific genomic locus. The main drawback of this technique is that the proccess is extremely inefficient, resulting in insertion rates below $0.1 \%$ (Brinster et al., 1989). This handicap can be bypassed by performing HR in Cell Cultures, where the few cells containing the intended modification after HR can be selected by introducing a selection cassette for resistance to a cytotoxic agent (Doetschman et al., 1988). Once the genetic modification has been introduced into the cell genome, there are only two possible strategies to obtain a genetically modified animal. The first method to be developed was the use of genetically modified Embryonic Stem Cells (ESCs) for embryonic aggregation. This strategy generates chimeric animals partly composed of genetically modified cells derived from the ESCs. By this approach, if the geneticallymodified ESCs-derived cells have formed germinal cells, the genetic modification could be transmitted to the offspring (Evans et al., 1985). The main limitation of this strategy was that it could only be applied to mice, as truly pluripotent ESCs -hence able to derive into germinal cells- could not be obtained in other species.

The second approach to produce genetically modified offspring from genetically modified cells is to perform Somatic Cell Nuclear Transfer (SCNT). In this case, the genetically modified nucleus of a somatic cell (usually a fibroblast) is reprogrammed by the ooplasm of an enucleated oocyte, resulting in an individual entirely composed by cells containing the genetic modification (Schnieke et al., 1997). This method allowed site-specific genome modifications in livestock species, but its application was highly restricted due to several technical limitations. SCNT is a technique difficult to master and very inefficient, resulting in less than $5 \%$ delivery rates (Wilmut et al., 1997; Kato et al., 2000) and often yielding to developmental defects associated with deffective epigenetic reprogramming of the donor genome. Furthermore, the donor somatic cells used for HR are mortal, unlike ESCs, so they can senescence over the multiple passages required to perform the genetic modification, leading to the loss of the transgenic cellular line or in even lower embryo developmental rates following SCNT. 
The technical constraints associated to targeted mutagenesis in farm animals have restricted the myriad of applications of genome modification in these species. Luckily, the advent of targeted mutagenesis techniques based on site-specific endonucleases has unleased the potential of genome editing in livestock species. Genome edited animals have been produced by different site-specific endonucleases such as Zinc-Finger Nucleases (ZFN) (Geurts et al., 2009; Whyte et al., 2011), Transcription Activator-Like Effector Nucleases (TALEN) (Tesson et al., 2011; Carlson et al., 2012) and Clustered Regularly Interspaced Short Palindromic Repeats (CRISPR) (Shen et al., 2013; Wang et al., 2013), but due to the ease of use and flexibility, CRISPR has become the most popular method.

\section{Mutagenesis induction by CRISPR}

CRISPR technology has its origin on an adaptive immune system from prokaryotes which retain memory of past viral exposures by storing short fragments of the viral DNA (Mojica et al., 2005). Between the diverse CRISPR system existing in nature, several class II systems have been adapted for genome editing in eukaryotes (Ran et al., 2015). The most commonly used system derives from the type II CRISPR system of the bacteria Streptococcus pyogenes, and it is composed by a Cas9 protein (CRISPR associated nuclease) and a sgRNA (single-guided RNA, which directs Cas 9 to the target site, composed by 20 nucleotides followed by -NGG) (Jinek et al., 2012).

CRISPR, as other site-specific endonucleases, is able to find its particular target across the genome and induce a DNA double stranded break (DSB) at that locus. In this sense, CRISPR per se does not generate any mutation, the mutation is actually generated by the endogenous DSB repair mechanisms of the eukaryotic cell. Eukaryotic cells mainly repair DSB by one of two mechanisms: Non-Homologous End Joining (NHEJ) or Homologous Recombination (HR). The editing process is dynamic, as CRISPR remains active after one repair mechanism has fixed the DSB (Figure 1). In this sense, if the repair mechanism has reconstituted the CRISPR target site or it has only slightly modified it, CRISPR will recognize the repaired site and generate a DSB again. The cycle will continue until CRISPR activity ceases or a modification in the target site impedes CRISPR recognition and thereby DSB generation. NHEJ is an error prone mechanism that often introduces or deletes bases (insertion/deletion, known as indel) at the DSB in the repair process (Moore and Haber, 1996), thereby producing mutated sequences that are not recognized by CRISPR. In contrast, HR uses another DNA molecule as template (Orr-Weaver et al., 1981) and thus, in the absence of any exogenous DNA, it reconstitutes CRISPR target site. Therefore, if CRISPR remains active after $H R$ repair, it will reproduce the DSB on the repaired site. In contrast, if a template for homologous recombination able to modify CRISPR target site is provided (Capecchi, 1989), this mechanism could be used to introduce DNA sequences at specific loci (KI).

\section{CRISPR for KO generation}

The indels generated by NHEJ are the most common way to generate a $\mathrm{KO}$ by CRISPR. For this aim, CRISPR components are directly injected into a zygote, and CRISPR target site should be located at the beginning of the Open Reading Frame (ORF) of the target gene. On that region, if the indel generated is not multiple of three, it will originate a disruption of the ORF (frame-shift mutation), leading to a truncated and non-functional peptide (i.e., a $\mathrm{KO}$ allele). However, as indels are randomly generated, some will be multiple of three, resulting in the insertion or deletion of few aminoacids, but leading to a probably functional protein (Figure 2). In other words, although virtually $100 \%$ gene editing efficiency can be achieved, $100 \% \mathrm{KO}$ generation is statistically unachievable, as some of the indels generated will be multiples of 3 and thereby will not disrupt gene translation. In this context, genotyping strategy should be able to detect all indels (alleles) generated on a given individual, as solely individuals containing only frame-disrupting indels can be considered as KO.

A strategy to increase the percentage of $\mathrm{KO}$ out of edited embryos may be the use of multiple guides for the same gene (Wang et al., 2015b; Chuang et al., 2016; Wang et al., 2016a; Wang et al., 2016b; Vilarino et al., 2017). Multiple guides lead to multiple DSB that may result in either the deletion of a large fragment within them, which may include the start codon, or in the alteration of the ORF at different points. However, this strategy holds several drawbacks: 1) the indel generated on downstream DSB may reconstitute again the ORF disrupted by a first indel, resulting only in an alteration of the fragment between both DSBs, leading to a partially modified protein with unpredictable functionality, which contrasts with the neat and simple alleles generated with a single target; 2) for the same reason, the genotyping is more complicated and difficult to interpret; and 3) it increases the chances of offtarget.

As it will be discussed below, one of the main advantages of CRISPR over HR is that it allows the direct generation of $\mathrm{KO}$ individuals by direct injection of CRISPR components into a zygote. Due to the low efficiency of the technique, HR achieves monoallelic modifications in either ES or fibroblasts, resulting in heterozygote founders that need to be crossed to obtain a homozygous $\mathrm{KO}$. The generation of a $\mathrm{KO}$ individual in one step (i.e. homozygous $\mathrm{KO}$ on $\mathrm{F} 0$ generation) is particularly useful to understand the role of specific genes during embryo development and it is extremely important to reduce the number of generations required to produce a $\mathrm{KO}$ animal in livestock species, where, in contrast to mice, generation times can be counted by years, rather than by months. 


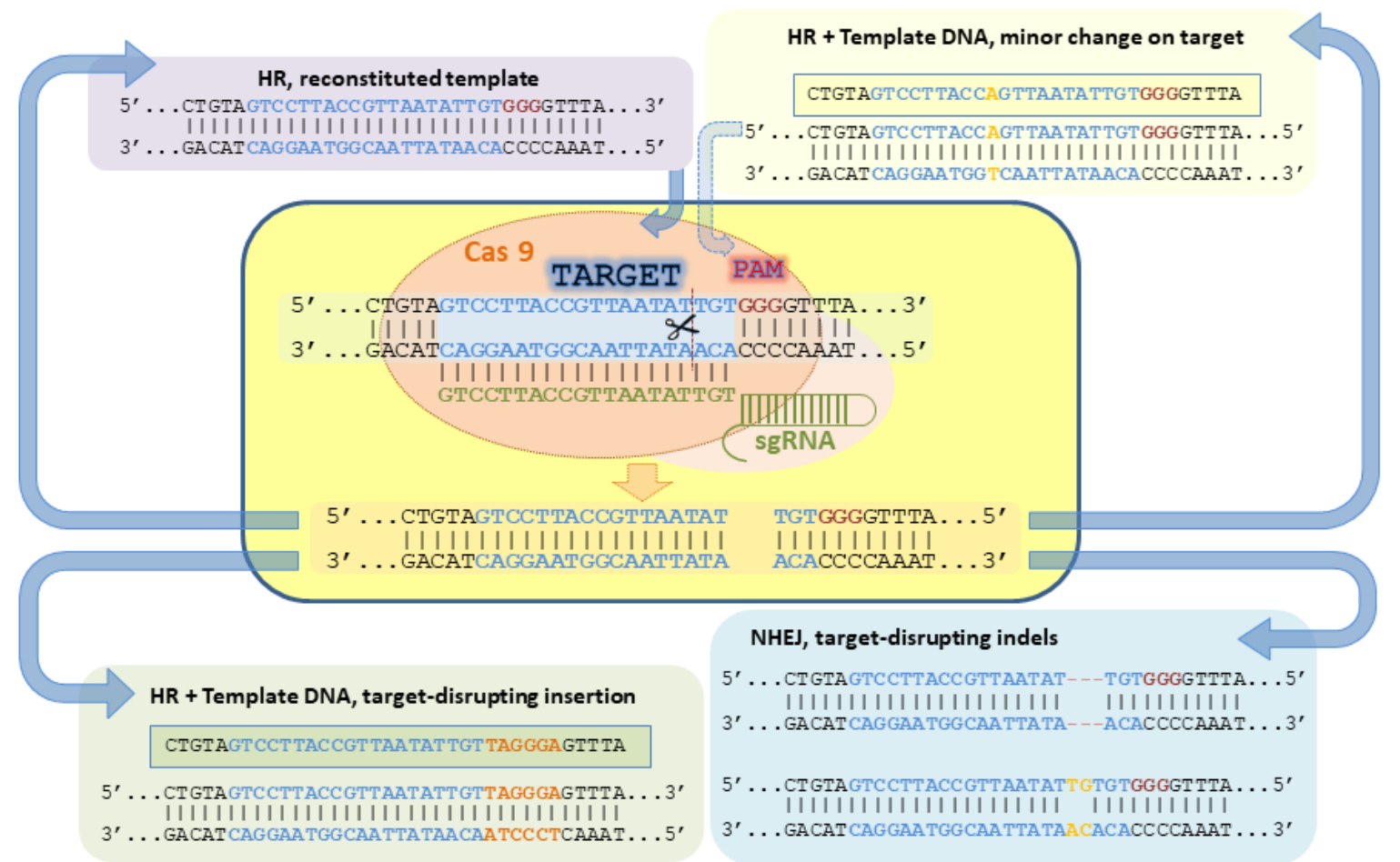

Figure 1. Dynamics of DSB repair by endogenous eukaryotic mechanisms (NHEJ or HR). Repairment by NHEJ often results in indels at the target site that impair CRISPR recognition. In contrast, repairment by HR reconstitutes the CRISPR target site unless a recombination template containing a target-disrupting insertion is provided. The reconstitution of the CRISPR target site leads to a new DSB at the repaired target unless CRISPR activity has ceased.
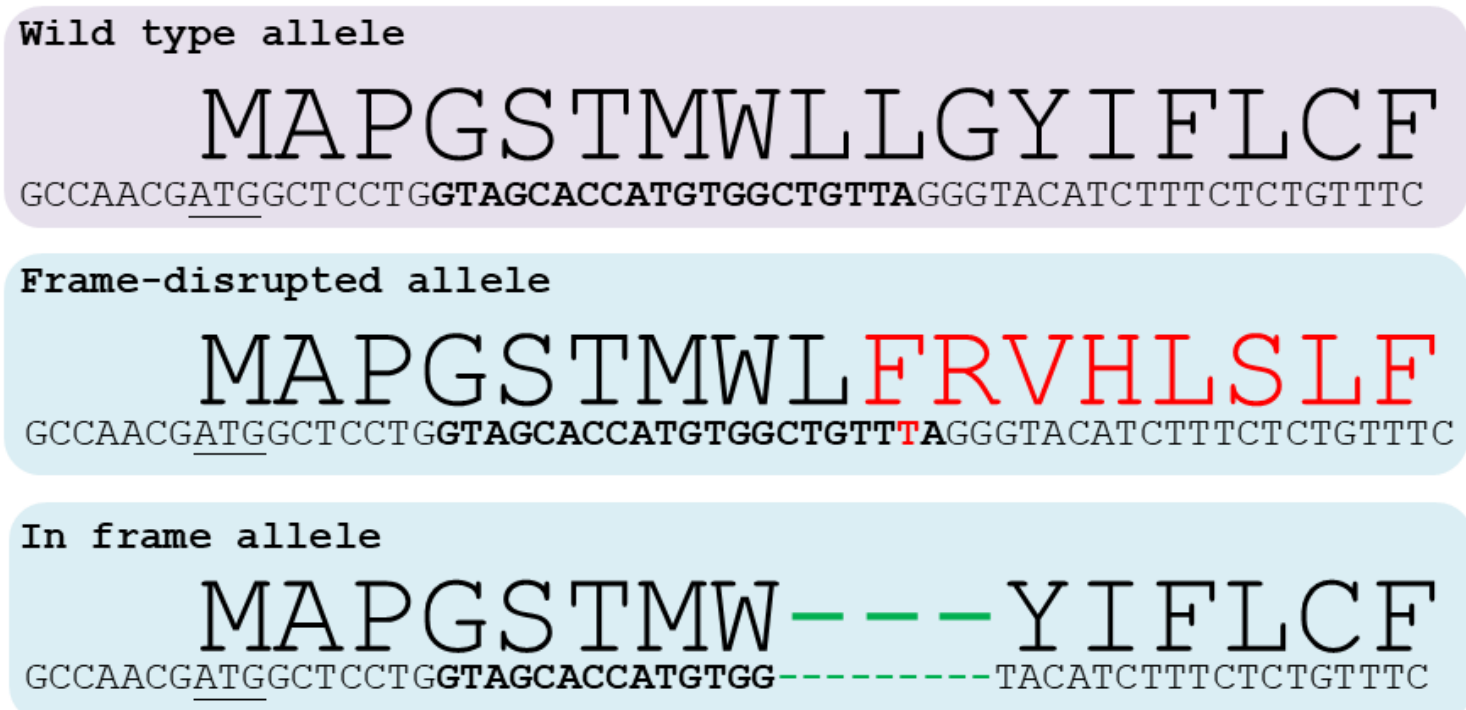

Figure 2. Examples of indels generated by CRISPR at the beginning of the coding region of rabbit $Z P 4$ gene. Wildtype, frame-disrupted and in frame alleles are shown. For each allele, aminoacid sequence is depicted in big letters that match the codons situated below, start codon (ATG) is underlined and CRISPR target site is marked in bold letters. On the frame-disrupted allele, a insertion of a single base (red T) disrupt the aminoacid sequence beyond that point. In contrast, a in frame indel consisting in a 9 bp deletion only eliminates 3 aminoacids, leaving the rest of the sequence unaltered. 


\section{Mosaicism impairs direct KO generation by CRISPR}

In the context of random generation of indels by NHEJ, a reduction in the number of alleles generated in a given individual is desired to obtain $\mathrm{KO}$ individuals: the more alleles an individual harbours, the less probable will be that all of them are framedisrupting. Ideally, indels should be generated at the $2 \mathrm{n} 2 \mathrm{c}$ stage, resulting in 2 alleles. However, DNA replication occurs soon after fertilization in most species and thus genome edition may occur after DNA replication $(2 \mathrm{n} 4 \mathrm{c})$, resulting in more than 2 alleles (Figure 3 ). This is phenomenon is called mosaicism, as it results in mosaic individuals composed by more than one cell population. Mosaicism was initially overlooked, as it is not a common problem in the generation of murine $\mathrm{KO}$ models (Bermejo-Alvarez et al., 2015), but most of the publications that have performed allele screening following CRISPR direct injection in zygotes have observed mosaicism in different species such as pigs (Hai et al., 2014; Sato et al., 2015; Wang et al., 2015c; Chuang et al., 2016; Kang et al., 2016; Petersen et al., 2016; Yu et al., 2016; Zhou et al., 2016; Burkard et al., 2017; Park et al., 2017; Whitworth et al., 2017), goats (Wang et al., 2016a), sheep (Crispo et al., 2015; Wang et al., 2016c; Vilarino et al., 2017; Zhang et al., 2017), cattle (Bevacqua et al., 2016) and rabbits (Yan et al., 2014; Honda et al., 2015; Guo et al., 2016; Lv et al., 2016; Song et al., 2016a; Song et al., 2016b; Sui et al., 2016; Yang et al., 2016; Yuan et al., 2016).

Although it was initially overlooked, the appearance of mosaicism is not surprising given that in most of the cases, conventional IVF or in vivo protocols used to collect zygotes for microinjection obtain them at or close to the $2 \mathrm{c} 4 \mathrm{n}$ state, which obviously results in at least 4 alleles following edition. In the case of bovine, conventional IVF co-incubates oocytes and spermatozoa for $20 \mathrm{~h}$ (Parrish et al., 1986), while DNA replication has been reported to occur between 8 and 18 hours postinsemination (Eid et al., 1994). The time of gamete coincubation used in bovine is roughly similar to those employed in sheep and goats, where pronuclear formation, which precedes DNA replication, occurs even earlier than in bovine (Mogas et al., 1997; Gomez et al., 1998). Pig IVF zygotes are usually obtained after a short 5-6 h gametes co-incubation aiming to reduce polyspermy, whereas according to studies performing sperm injection (ICSI) the onset of S-phase occurs $~ 10$ $\mathrm{h}$ after injection (Kim et al., 2003). However, pronuclei formation is delayed about $4 \mathrm{~h}$ in ICSI-derived embryos (Kim et al., 2003) compared to IVF-derived counterparts (Matas et al., 2003), and thus porcine zygotes may be at or very close the onset of DNA replication right after IVF. Similarly, in vivo porcine zygotes are usually collected at 52-60 hours post-hCG and DNA replication has been reported to occur between 56-60 h post hCG (Laurincik et al., 1995). Rabbit zygotes are fertilized at $\sim 14$ hours post-mating (Pincus and Enzmann, 1932) and replicate its DNA 3-6 $\mathrm{h}$ after sperm penetration (Oprescu and Thibault, 1965; Szollosi, 1966). Although it is unclear how long the genome editing mediated by CRISPR combined to the definitive repair of the DSB lasts, it seems that strategies focussed on an earlier delivery of CRISPR components may help to reduce mosaicism.

a
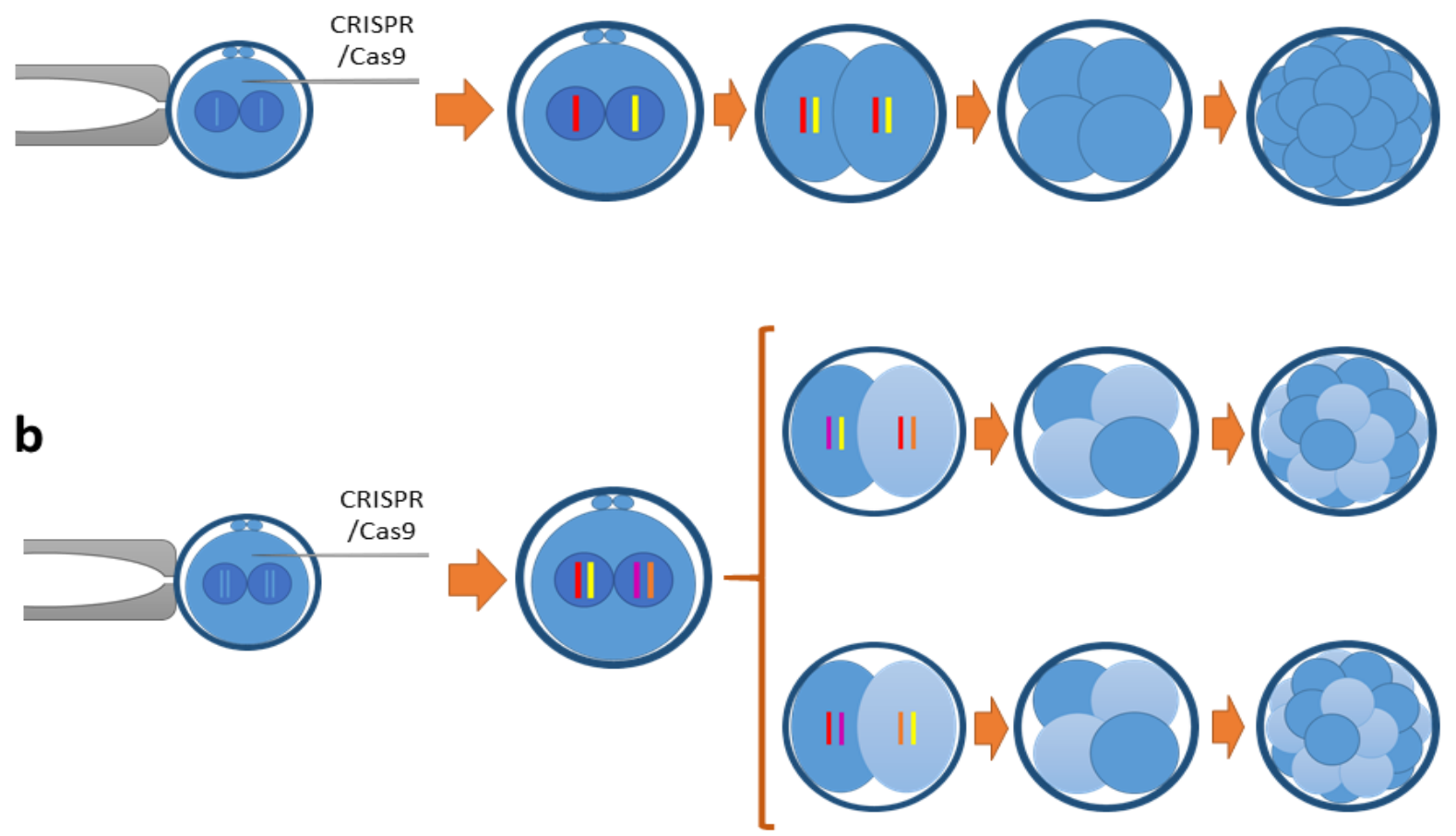

Figure 3. Possible outcomes following CRISPR microinjection into zygotes and NHEJ repair: a) If the DSBs and their definite repairs occur before DNA replication, at the 2n2c stage, 2 indels (alleles) are generated; or b) If DNA has been already replicated $(4 n 4 c)$, CRISPR edition generates 4 alleles that seggregate following first cleavage, leading to two populations of blastomeres harbouring 2 alleles each. 


\section{CRISPR for KI generation}

Targeted insertion of a given sequence can be achieved by homologous recombination (Orr-Weaver et al., 1981), which alone (i.e. limited to the incorporation of a sequence containing homology arms) is a very inefficient technique (Brinster et al., 1989) that requires the use of an intermediary (ESCs or fibroblasts cultures) to generate a genetically modified animal (Doetschman et al., 1988; Schnieke et al., 1997). However, when a DSB is produced at the HR target locus, the efficiency of HR is improved by $>1000$ fold (Moehle et al., 2007). Under this improved efficiency, the insertion can be directly achieved by co-injecting a HR template and CRISPR components in zygotes, especially when the insert size is small (Yang et al., 2014). However, in farm animals the use of fibroblasts as intermediaries followed by SCNT remains being the most commonly used strategy to generate KI animals, as it ensures that all animals generated will carry the intended mutation. For this purpose, the combination of CRISPR +HR template has become the method of choice over HR alone, as the boosted HR efficiency also facilitates genome modification in cell cultures.

The repair template can be double or singlestrand DNA (dsDNA or ssDNA). ssDNA often result in higher editing efficiency with reduced random insertions (Ran et al., 2013b), but circular vectors are also effective and convenient to introduce long inserts and homology arms (Yang et al., 2014). As previously mentioned, an essential requisite of the HR template to be used combined with CRISPR is that the insertion should disrupt CRISPR recognition site, as otherwise, CRISPR will reproduce the DSB at the reconstituted target site. This can be difficult to achieve when single nucleotide modification is intended, as it can be the case for the introgression of a SNP.

A strategy employed for KI generation is the use of nickase, a mutant form of Cas9 that only produces a break in one strand (Ran et al., 2013a). For this purpose, nickase should be co-injected with two sgRNAs (one for each strand), which, in contrast to Cas9, leaves long 5'overhangs that may benefit HR, although not clear consensus has been reached about its putative increased efficiency over conventional Cas9. Another aspect that can be modified from the $\mathrm{KO}$ generation protocol is that, as double insertion may be difficult to achieve, the generation of mosaics may be beneficial, as it increases the chances of generating a founder with at least 1 allele harbouring the insertion. Other strategies to improve HR efficiency include the use of NHEJ inhibitors such as SCR-7 (Singh et al., 2015) or HR activators as RS-1 (Song et al., 2016a).

The insertion of a particular sequence at a specific locus allows precise reporter experiments using the endogenous promoter/s and enhancer/s or the endogenously controlled expression of a transgene, among others, but can also be used to generate $\mathrm{KO}$ models. For this purpose, a stop codon can be inserted at the beginning of the ORF of a gene. This strategy holds the advantage over conventional $\mathrm{KO}$ generation by the random NHEJ-created indels of being easier to genotype, as a restriction enzyme site can be introduced along the stop codon, which allows a sequencing-free identification of the founder offspring. HR can also be used to introduce loxP or FRT sites flanking a target exon for the conditional ablation of genes by Cre-lox (Orban et al., 1992) or FLP-FRT (Buchholz et al., 1998) recombination systems.

\section{Applications of CRISPR in livestock research}

Genome modification in farm animals holds a myriad of applications on different fields, including the production of therapeutic proteins (Spencer et al., 2005; van Veen et al., 2012; Sheridan, 2016), the generation of biomodels for human diseases (reviewed by Whitelaw et al., 2016), the creation of animal organs less prone to rejection after transplantation (reviewed by Whyte and Prather, 2011), the development of human organs generated into an animal host (Wu et al., 2017), or, maybe the closest applications to the farm: the improvement of productive rates, animal products, animal health or the environmental impact of farming via genetically modified livestock (reviewed by LamasToranzo et al., 2017). However, the latter applications are currently stopped by a ban (or lack of approval) of animal products derived from any genetically modified animals (GMAs) for human consumption. Legislation of different countries is slowly adapting to the new scenario created by genome editing (reviewed recently by Van Eenennaam, 2018), and the classifications of GMAs into different types depending on the kind of genetic modifications performed could lead to different sets of requirements for approval (discussed in LamasToranzo et al., 2017). In any case, today CRISPR constitutes a powerful tool for research in livestock species, being readily able to generate knowledge applicable to non-edited livestock.

As it has been previously explained, the benefits of genome modification in research have been largely limited to the mouse model, leaving livestock research devoid of KO or KI models. Although the knowledge generated by some $\mathrm{KO}$ or $\mathrm{KI}$ murine models can and has been applicable to some aspect of the physiology of livestock species, some processes such as some involved in reproduction, embryo development or infectious disease are highly species specific, impeding the extrapolation of data between species. Besides, CRISPR technology allows to unequivocally prove the role of a particular allele detected on a Genome-wide Association Study (GWAS) on productive traits, which may be helpful when population size or allele frequency is too small to drawn proper conclusions or to test whether such allele will produce a similar phenotype in other genetic background or species. Examples of alleles known to affect production that have been generated by CRISPR include myostatin KOs, which enhance muscular development in CRISPR-edited pigs (Wang et al., 2015a), goats (Wang et al., 2015b), sheep (Crispo et al., 2015) and rabbits (Lv et al., 2016); FGF5 KO in goats (Wang et al., 2016a), which improves cashmere 
production; and the POLLED allele introduced in horned bovine genetic lines (Tan et al., 2013).

The direct generation of $\mathrm{KO}$ by CRISPR is particularly advantageous for its use on experiments aiming to elucidate the molecular aspects of embryo development, as it allows to restrict the ablation from the zygote stage onwards. This contrasts to the approach commonly used in murine $\mathrm{KO}$ models, where the low efficiency of HR alone or the lethal phenotype of the homozygous $\mathrm{KO}$ force the generation of homozygous $\mathrm{KO}$ embryos by the cross of heterozygous (wt/KO) parents (Evans et al., 1985). In this context, the gametes originating the $\mathrm{KO}$ embryos have been developed in haploinsuficiency (they are wt/KO and then wt or KO as meiosis progresses; Pattabiraman et al., 2015), which may lead to confusing conclusions about whether the gene disruption exerted its effect during gametogenesis or during early development. This is especially relevant when the gene of study is involved in stable and long term alterations such as epigenome remodelling (de Frutos et al., 2016). Apart from this advantage, which also applies to the mouse model, the direct generation of a KO embryo circumvents the need of genetically modified animals, as only wt gametes are required to produce $\mathrm{KO}$ embryos. Embryonic development in farm animals is known to greatly differ in terms of epigenetic events (Bermejo-Alvarez et al., 2010) and early lineage segregation determinants (Berg et al., 2011) to the mouse model. Particularly in ungulates, which accounts for the most relevant mammalian livestock species worldwide, the blastocysts does not attach after hatching as it occurs in rodents or humans. Instead, it undergoes a series of developmental events including early and late gastrulation in a period termed embryo elongation. These developmental processes are poorly understood and research on this area is particularly relevant to improve reproductive rates, as failures during this period account for most reproductive losses in pigs (Bennett and Leymaster, 1989) and cattle (Dunne et al., 2000; Santos et al., 2004; Berg et al., 2010).

Another field that can be greatly benefited from the use of GMA is the research on infectious diseases, especially given the high species specificity of several pathogens. Cattle with increased resistance to tuberculosis have been generated by CRISPR-mediated insertion of natural resistance-associated macrophage protein-1 (NRAMP1) (Gao et al., 2017). CRISPR has also been used to generate pigs resistant to African Swine Fever by the substitution of the porcine gene RELA for its orthologue from a closely related species that is resistant to the infection: the warthog (Lillico et al., 2016). Pigs resistant to the infection of the porcine reproductive and respiratory syndrome virus (PRRVS), a viral disease difficult to eradicate and responsible for major losses in the pig industry, have been generated by CRISPR (Whitworth et al., 2016). Although these models were generated thinking about a future use for human consumption, they already provide insights about the pathogenesis and entry ways of infectious agents that can be used to develop therapeutic or prophylactic treatments in conventional non-edited animals.

\section{Concluding remarks}

Genome editing in farm animals has been hampered by the inefficiency and difficulty of early techniques, based on HR combined with SCNT. This obstacle has deprived research in livestock species of the definite answers provided by $\mathrm{KO}$ models. The advent of site-specific endonucleases and particularly CRISPR, the easiest to tailor between them, is meant to inaugurate a new era in livestock research. This technology allows direct targeted genome modification in one step by a simple microinjection in zygotes, allowing to unequivocally know the role of a particular gene product on a given process. The novel affordability of $\mathrm{KO}$ and $\mathrm{KI}$ models for livestock research can improve the quality of scientific results, as it grants the exchange of descriptive and correlational approaches by experimental ones.

\section{Acknowledgements}

This work was supported by Grants RYC2012-10193 and AGL2014-58739-R from the Spanish Ministry of Economy and Competitiveness and StG757886 from the European Research Council. ILT is supported by an FPI contract and PRI by the Talent Attraction Program from Madrid Region Government. The authors appologise to those scientists whose important contributions may have been omitted due to space limitations

\section{References}

Bennett GL, Leymaster KA. 1989. Integration of ovulation rate, potential embryonic viability and uterine capacity into a model of litter size in swine. J Anim Sci, 67:1230-1241

Berg DK, van Leeuwen J, Beaumont S, Berg M, Pfeffer PL. 2010. Embryo loss in cattle between Days 7 and 16 of pregnancy. Theriogenology, 73:250-260.

Berg DK, Smith CS, Pearton DJ, Wells DN, Broadhurst R, Donnison M, Pfeffer PL. 2011. Trophectoderm lineage determination in cattle. Dev Cell, 20:244-255.

Bermejo-Alvarez P, Rizos D, Rath D, Lonergan P, Gutierrez-Adan A. 2010. Sex determines the expression level of one third of the actively expressed genes in bovine blastocysts. Proc Natl Acad Sci U S A, 107:3394-3399.

Bermejo-Alvarez P, Ramos-Ibeas P, Park KE, Powell AP, Vansandt L, Derek B, Ramirez MA, Gutierrez-Adan A, Telugu BP. 2015. Tet-mediated imprinting erasure in H19 locus following reprogramming of spermatogonial stem cells to induced pluripotent stem cells. Sci Rep, 5:13691.

Bevacqua RJ, Fernandez-Martin R, Savy V, Canel NG, Gismondi MI, Kues WA, Carlson DF, Fahrenkrug SC, Niemann H, Taboga OA, Ferraris S, Salamone DF. 2016. Efficient edition of the bovine PRNP prion gene in somatic cells and IVF embryos using the CRISPR/Cas9 system. Theriogenology, 86:1886-1896 e1881. 
Brinster RL, Braun RE, Lo D, Avarbock MR, Oram F, Palmiter RD. 1989. Targeted correction of a major histocompatibility class II E alpha gene by DNA microinjected into mouse eggs. Proc Natl Acad Sci U S A, 86:7087-7091.

Buchholz F, Angrand PO, Stewart AF. 1998. Improved properties of FLP recombinase evolved by cycling mutagenesis. Nat Biotechnol, 16:657-662.

Burkard C, Lillico SG, Reid E, Jackson B, Mileham AJ, Ait-Ali T, Whitelaw CB, Archibald AL. 2017. Precision engineering for PRRSV resistance in pigs: Macrophages from genome edited pigs lacking CD163 SRCR5 domain are fully resistant to both PRRSV genotypes while maintaining biological function. PLoS Pathog, 13:e1006206.

Capecchi MR. 1989. Altering the genome by homologous recombination. Science, 244:1288-1292.

Carlson DF, Tan W, Lillico SG, Stverakova D, Proudfoot C, Christian M, Voytas DF, Long CR, Whitelaw CB, Fahrenkrug SC. 2012. Efficient TALEN-mediated gene knockout in livestock. Proc Natl Acad Sci U S A, 109:17382-17387.

Chan AW, Homan EJ, Ballou LU, Burns JC, Bremel RD. 1998. Transgenic cattle produced by reversetranscribed gene transfer in oocytes. Proc Natl Acad Sci U S A, 95:14028-14033.

Chuang CK, Chen CH, Huang CL, Su YH, Peng SH, Lin TY, Tai HC, Yang TS, Tu CF. 2016. Generation of GGTA1 Mutant Pigs by Direct Pronuclear Microinjection of CRISPR/Cas9 Plasmid Vectors. Anim Biotechnol, 1-8.

Crispo M, Mulet AP, Tesson L, Barrera N, Cuadro F, dos Santos-Neto PC, Nguyen TH, Creneguy A, Brusselle L, Anegon I, Menchaca A. 2015. Efficient Generation of Myostatin Knock-Out Sheep Using CRISPR/Cas9 Technology and Microinjection into Zygotes. PLOS ONE, 10:e0136690.

De Frutos C, Lopez-Cardona AP, Fonseca Balvis N, Laguna-Barraza R, Rizos D, Gutierrez-Adan A, Bermejo-Alvarez P. 2016. Spermatozoa telomeres determine telomere length in early embryos and offspring. Reproduction, 151:1-7.

Doetschman T, Maeda N, Smithies O. 1988. Targeted mutation of the Hprt gene in mouse embryonic stem cells. Proc Natl Acad Sci U S A, 85:8583-8587.

Dunne LD, Diskin MG, Sreenan JM. 2000. Embryo and foetal loss in beef heifers between day 14 of gestation and full term. Anim Reprod Sci, 58:39-44.

Eid LN, Lorton SP, Parrish JJ. 1994. Paternal influence on S-phase in the first cell cycle of the bovine embryo. Biol Reprod, 51:1232-1237.

Evans MJ, Bradley A, Kuehn MR, Robertson EJ. 1985. The ability of EK cells to form chimeras after selection of clones in G418 and some observations on the integration of retroviral vector proviral DNA into EK cells. Cold Spring Harb Symp Quant Biol, 50:685689

Gao Y, Wu H, Wang Y, Liu X, Chen L, Li Q, Cui C, Zhang J, Zhang Y. 2017. Single Cas9 nickase induced generation of NRAMP1 knockin cattle with reduced off-target effects. Genome Biol, 18:13.

Geurts AM, Cost GJ, Freyvert Y, Zeitler B, Miller
JC, Choi VM, Jenkins SS, Wood A, Cui X, Meng X, Vincent A, Lam S, Michalkiewicz M, Schilling R, Foeckler J, Kalloway S, Weiler H, Menoret S, Anegon I, Davis GD, Zhang L, Rebar EJ, Gregory PD, Urnov FD, Jacob HJ, Buelow R. 2009. Knockout rats via embryo microinjection of zinc-finger nucleases. Science, 325:433.

Gomez MC, Catt SL, Gillan L, Catt JW, Evans G, Maxwell WM. 1998. Time course of pronuclear formation and fertilisation after insemination in vitro and intracytoplasmic sperm injection of in vitro matured sheep oocytes. Zygote, 6:261-270.

Guo R, Wan Y, Xu D, Cui L, Deng M, Zhang G, Jia R, Zhou W, Wang Z, Deng K, Huang M, Wang F, Zhang Y. 2016. Generation and evaluation of Myostatin knock-out rabbits and goats using CRISPR/Cas9 system. Sci Rep, 6:29855.

Hai T, Teng F, Guo R, Li W, Zhou Q. 2014. One-step generation of knockout pigs by zygote injection of CRISPR/Cas system. Cell Res, 24:372-375.

Hammer RE, Pursel VG, Rexroad CE, Jr, Wall RJ, Bolt DJ, Ebert KM, Palmiter RD, Brinster RL. 1985. Production of transgenic rabbits, sheep and pigs by microinjection. Nature, 315:680-683.

Honda A, Hirose M, Sankai T, Yasmin L, Yuzawa K, Honsho K, Izu H, Iguchi A, Ikawa M, Ogura A 2015. Single-step generation of rabbits carrying a targeted allele of the tyrosinase gene using CRISPR/Cas9. Exp Anim, 64:31-37.

Jinek M, Chylinski K, Fonfara I, Hauer M, Doudna JA, Charpentier E. 2012. A programmable dual-RNAguided DNA endonuclease in adaptive bacterial immunity. Science, 337:816-821.

Kang JT, Cho B, Ryu J, Ray C, Lee EJ, Yun YJ, Ahn S, Lee J, Ji DY, Jue N, Clark-Deener S, Lee K, Park KW. 2016. Biallelic modification of IL2RG leads to severe combined immunodeficiency in pigs. Reprod Biol Endocrinol, 14:74.

Kato Y, Tani T, Tsunoda Y. 2000. Cloning of calves from various somatic cell types of male and female adult, newborn and fetal cows. $J$ Reprod Fertil, 120:231-237.

Kim BK, Cheon SH, Lee YJ, Choi SH, Cui XS, Kim NH. 2003. Pronucleus formation, DNA synthesis and metaphase entry in porcine oocytes following intracytoplasmic injection of murine spermatozoa. Zygote, 11:261-270.

Lamas-Toranzo I, Guerrero-Sánchez J, MirallesBover H, Alegre-Cid G, Pericuesta E, BermejoÁlvarez P. 2017. CRISPR is knocking on barn door. Reprod Domest Anim, 52(Suppl 4):39-47.

Laurincik J, Hyttel P, Kopecny V. 1995. DNA synthesis and pronucleus development in pig zygotes obtained in vivo: an autoradiographic and ultrastructural study. Mol Reprod Dev, 40:325-332.

Lillico SG, Proudfoot C, King TJ, Tan W, Zhang L, Mardjuki R, Paschon DE, Rebar EJ, Urnov FD, Mileham AJ, McLaren DG, Whitelaw CB. 2016. Mammalian interspecies substitution of immune modulatory alleles by genome editing. Sci Rep, 6:21645. Lv Q, Yuan L, Deng J, Chen M, Wang Y, Zeng J, Li Z, Lai L. 2016. Efficient Generation of Myostatin Gene 
Mutated Rabbit by CRISPR/Cas9. Sci Rep, 6:25029. Matas C, Coy P, Romar R, Marco M, Gadea J, Ruiz S. 2003. Effect of sperm preparation method on in vitro fertilization in pigs. Reproduction, 125:133-141.

Moehle EA, Rock JM, Lee YL, Jouvenot Y, DeKelver RC, Gregory PD, Urnov FD, Holmes MC. 2007. Targeted gene addition into a specified location in the human genome using designed zinc finger nucleases. Proc Natl Acad Sci U S A, 104:3055-3060.

Mogas T, Palomo MJ, Izquierdo MD, Paramio MT. 1997. Morphological events during in vitro fertilization of prepubertal goat oocytes matured in vitro. Theriogenology, 48:815-829.

Mojica FJ, Diez-Villasenor C, Garcia-Martinez J, Soria E. 2005. Intervening sequences of regularly spaced prokaryotic repeats derive from foreign genetic elements. J Mol Evol, 60:174-182.

Moore JK, Haber JE. 1996. Cell cycle and genetic requirements of two pathways of nonhomologous endjoining repair of double-strand breaks in Saccharomyces cerevisiae. Mol Cellular Biol, 16:2164-2173.

Oprescu S, Thibault C. 1965. Duplication de 1'ADN dans les oeufs de lapine après la fécondation. Ann Biol Anim Biochem Biophy, 5:151-156.

Orban PC, Chui D, Marth JD. 1992. Tissue- and sitespecific DNA recombination in transgenic mice. Proc Natl Acad Sci U S A, 89:6861-6865.

Orr-Weaver TL, Szostak JW, Rothstein RJ. 1981. Yeast transformation: a model system for the study of recombination. Proc Natl Acad Sci US A, 78:63546358.

Park KE, Powell A, Sandmaier SE, Kim CM, Mileham A, Donovan DM, Telugu BP. 2017. Targeted gene knock-in by CRISPR/Cas ribonucleoproteins in porcine zygotes. Sci Rep, 7:42458.

Parrish JJ, Susko-Parrish JL, Leibfried-Rutledge ML, Critser ES, Eyestone WH, First NL. 1986. Bovine in vitro fertilization with frozen-thawed semen. Theriogenology, 25:591-600.

Pattabiraman S, Baumann C, Guisado D, Eppig JJ, Schimenti JC, De La Fuente R. 2015. Mouse BRWD1 is critical for spermatid postmeiotic transcription and female meiotic chromosome stability. J Cell Biol, 208:53-69.

Petersen B, Frenzel A, Lucas-Hahn A, Herrmann D, Hassel P, Klein S, Ziegler M, Hadeler KG, Niemann H. 2016. Efficient production of biallelic GGTA1 knockout pigs by cytoplasmic microinjection of CRISPR/Cas9 into zygotes. Xenotransplantation, 23:338-346

Pincus G, Enzmann EV. 1932. Fertilisation in the Rabbit. J Exp Biol, 9:403-408.

Ran FA, Hsu PD, Lin CY, Gootenberg JS, Konermann S, Trevino AE, Scott DA, Inoue A, Matoba S, Zhang Y, Zhang F. 2013a. Double nicking by RNA-guided CRISPR Cas9 for enhanced genome editing specificity. Cell, 154:1380-1389.

Ran FA, Hsu PD, Wright J, Agarwala V, Scott DA, Zhang F. 2013b. Genome engineering using the CRISPR-Cas9 system. Nat Protoc, 8:2281-2308.

Ran FA, Cong L, Yan WX, Scott DA, Gootenberg JS, Kriz AJ, Zetsche B, Shalem O, Wu X, Makarova
KS, Koonin EV, Sharp PA, Zhang F. 2015. In vivo genome editing using Staphylococcus aureus Cas9. Nature, 520:186-191.

Santos JE, Thatcher WW, Chebel RC, Cerri RL, Galvao KN. 2004. The effect of embryonic death rates in cattle on the efficacy of estrus synchronization programs. Anim Reprod Sci, 82-83:513-535.

Sato M, Koriyama M, Watanabe S, Ohtsuka M, Sakurai T, Inada E, Saitoh I, Nakamura S, Miyoshi K. 2015. Direct Injection of CRISPR/Cas9-Related mRNA into Cytoplasm of Parthenogenetically Activated Porcine Oocytes Causes Frequent Mosaicism for Indel Mutations. Int J Mol Sci, 16:17838-17856.

Schnieke AE, Kind AJ, Ritchie WA, Mycock K, Scott AR, Ritchie M, Wilmut I, Colman A, Campbell KH. 1997. Human factor IX transgenic sheep produced by transfer of nuclei from transfected fetal fibroblasts. Science, 278:2130-2133.

Shemesh M, Gurevich M, Harel-Markowitz E, Benvenisti L, Shore LS, Stram Y. 2000. Gene integration into bovine sperm genome and its expression in transgenic offspring. Mol Reprod Dev, 56:306-308.

Shen B, Zhang J, Wu H, Wang J, Ma K, Li Z, Zhang $\mathbf{X}$, Zhang P, Huang X. 2013. Generation of genemodified mice via Cas9/RNA-mediated gene targeting. Cell Res, 23:720-723.

Sheridan C. 2016. FDA approves 'farmaceutical' drug from transgenic chickens. Nat Biotechnol, 34:117-119.

Singh P, Schimenti JC, Bolcun-Filas E. 2015. A mouse geneticist's practical guide to CRISPR applications. Genetics, 199:1-15.

Song J, Yang D, Xu J, Zhu T, Chen YE, Zhang J. 2016a. RS-1 enhances CRISPR/Cas9- and TALENmediated knock-in efficiency. Nat Commun, 7:10548.

Song Y, Yuan L, Wang Y, Chen M, Deng J, Lv Q, Sui T, Li Z, Lai L. 2016b. Efficient dual sgRNAdirected large gene deletion in rabbit with CRISPR/Cas9 system. Cell Mol Life Sci, 73:2959-2968. Spencer LT, Humphries JE, Brantly ML. 2005. Antibody response to aerosolized transgenic human alpha1-antitrypsin. N Engl J Med, 352:2030-2031.

Sui T, Yuan L, Liu H, Chen M, Deng J, Wang Y, Li Z, Lai L. 2016. CRISPR/Cas9-mediated mutation of PHEX in rabbit recapitulates human X-linked hypophosphatemia (XLH). Hum Mol Genet, 25:26612671.

Szollosi D. 1966. Time and duration of DNA synthesis in rabbit eggs after sperm penetration. Anat Rec, 154:209-212.

Tan W, Carlson DF, Lancto CA, Garbe JR, Webster DA, Hackett PB, Fahrenkrug SC. 2013. Efficient nonmeiotic allele introgression in livestock using custom endonucleases. Proc Natl Acad Sci U S A, 110:16526-16531.

Tesson L, Usal C, Menoret S, Leung E, Niles BJ, Remy S, Santiago Y, Vincent AI, Meng X, Zhang L, Gregory PD, Anegon I, Cost GJ. 2011. Knockout rats generated by embryo microinjection of TALENs. Nat Biotechnol, 29:695-696.

Van Eenennaam AL. 2018. The importance of a novel product risk-based trigger for gene editing regulation in food animal species. The CRISPR Journal, 1. 
https://doi.org/10.1089/crispr.2017.0023

van Veen HA, Koiter J, Vogelezang CJ, van Wessel N, van Dam T, Velterop I, van Houdt K, Kupers L, Horbach D, Salaheddine M, Nuijens JH, Mannesse ML. 2012. Characterization of recombinant human C1 inhibitor secreted in milk of transgenic rabbits. $J$ Biotechnol, 162:319-326.

Vilarino M, Rashid ST, Suchy FP, McNabb BR, van der Meulen T, Fine EJ, Ahsan S, Mursaliyev N, Sebastiano V, Diab SS, Huising MO, Nakauchi H, Ross PJ. 2017. CRISPR/Cas9 microinjection in oocytes disables pancreas development in sheep. Sci Rep, 7:17472.

Wang H, Yang H, Shivalila CS, Dawlaty MM, Cheng AW, Zhang F, Jaenisch R. 2013. One-step generation of mice carrying mutations in multiple genes by CRISPR/Cas-mediated genome engineering. Cell, 153:910-918.

Wang K, Ouyang H, Xie Z, Yao C, Guo N, Li M, Jiao H, Pang D. 2015a. Efficient Generation of Myostatin Mutations in Pigs Using the CRISPR/Cas9 System. Sci Rep, 5:16623.

Wang X, Yu H, Lei A, Zhou J, Zeng W, Zhu H, Dong Z, Niu Y, Shi B, Cai B, Liu J, Huang S, Yan H, Zhao X, Zhou G, He X, Chen X, Yang Y, Jiang Y, Shi L, Tian X, Wang Y, Ma B, Huang X, Qu L, Chen Y. 2015b. Generation of gene-modified goats targeting MSTN and FGF5 via zygote injection of CRISPR/Cas9 system. Sci Rep, 5:13878.

Wang Y, Du Y, Shen B, Zhou X, Li J, Liu Y, Wang J, Zhou J, Hu B, Kang N, Gao J, Yu L, Huang X, Wei H. 2015c. Efficient generation of gene-modified pigs via injection of zygote with Cas9/sgRNA. Sci Rep, 5:8256.

Wang X, Cai B, Zhou J, Zhu H, Niu Y, Ma B, Yu H, Lei A, Yan H, Shen Q, Shi L, Zhao X, Hua J, Huang X, Qu L, Chen Y. 2016a. Disruption of FGF5 in Cashmere Goats Using CRISPR/Cas9 Results in More Secondary Hair Follicles and Longer Fibers. PLoS ONE, 11:e0164640.

Wang X, Cao C, Huang J, Yao J, Hai T, Zheng Q, Zhang H, Qin G, Cheng J, Wang Y, Yuan Z, Zhou Q, Wang H, Zhao J. 2016b. One-step generation of triple gene-targeted pigs using CRISPR/Cas9 system. Sci Rep, 6:20620.

Wang X, Niu Y, Zhou J, Yu H, Kou Q, Lei A, Zhao X, Yan H, Cai B, Shen Q, Zhou S, Zhu H, Zhou G, Niu W, Hua J, Jiang Y, Huang X, Ma B, Chen Y. 2016c. Multiplex gene editing via CRISPR/Cas9 exhibits desirable muscle hypertrophy without detectable off-target effects in sheep. Sci Rep, 6:32271.

Whitelaw CB, Sheets TP, Lillico SG, Telugu BP. 2016. Engineering large animal models of human disease. J Pathol, 238:247-256.

Whitworth KM, Rowland RR, Ewen CL, Trible BR, Kerrigan MA, Cino-Ozuna AG, Samuel MS, Lightner JE, McLaren DG, Mileham AJ, Wells KD, Prather RS. 2016. Gene-edited pigs are protected from porcine reproductive and respiratory syndrome virus.
Nat Biotechnol, 34:20-22.

Whitworth KM, Benne JA, Spate LD, Murphy SL, Samuel MS, Murphy CN, Richt JA, Walters E, Prather RS, Wells KD. 2017. Zygote injection of CRISPR/Cas9 RNA successfully modifies the target gene without delaying blastocyst development or altering the sex ratio in pigs. Transgenic Res, 26:97107.

Whyte JJ, Prather RS. 2011. Genetic modifications of pigs for medicine and agriculture. Mol Reprod Dev, 78:879-891.

Whyte JJ, Zhao J, Wells KD, Samuel MS, Whitworth KM, Walters EM, Laughlin MH, Prather RS. 2011. Gene targeting with zinc finger nucleases to produce cloned eGFP knockout pigs. Mol Reprod Deve, $78: 2$.

Wilmut I, Schnieke AE, McWhir J, Kind AJ, Campbell KH. 1997. Viable offspring derived from fetal and adult mammalian cells. Nature, 385:810-813.

Wu J, Platero-Luengo A, Sakurai M, Sugawara A, Gil MA, Yamauchi T, Suzuki K, Bogliotti YS, Cuello C, Morales Valencia M, Okumura D, Luo J, Vilarino M, Parrilla I, Soto DA, Martinez CA, Hishida T, Sanchez-Bautista S, Martinez-Martinez ML, Wang H, Nohalez A, Aizawa E, Martinez-Redondo P, Ocampo A, Reddy P, Roca J, Maga EA, Esteban CR, Berggren WT, Nunez Delicado E, Lajara J, Guillen I, Guillen P, Campistol JM, Martinez EA, Ross PJ, Izpisua Belmonte JC. 2017. Interspecies Chimerism with Mammalian Pluripotent Stem Cells. Cell, 168:473486 e415.

Yan Q, Zhang Q, Yang H, Zou Q, Tang C, Fan N, Lai L. 2014. Generation of multi-gene knockout rabbits using the Cas9/gRNA system. Cell Regen, 3:12.

Yang D, Song J, Zhang J, Xu J, Zhu T, Wang Z, Lai L, Chen YE. 2016. Identification and characterization of rabbit ROSA26 for gene knock-in and stable reporter gene expression. Sci Rep, 6:25161.

Yang H, Wang H, Jaenisch R. 2014. Generating genetically modified mice using CRISPR/Cas-mediated genome engineering. Nature protocols, 9:1956-1968.

Yu HH, Zhao H, Qing YB, Pan WR, Jia BY, Zhao HY, Huang XX, Wei HJ. 2016. Porcine Zygote Injection with Cas9/sgRNA Results in DMD-Modified Pig with Muscle Dystrophy. Int J Mol Sci, 17:

Yuan L, Sui T, Chen M, Deng J, Huang Y, Zeng J, Lv Q, Song Y, Li Z, Lai L. 2016. CRISPR/Cas9mediated GJA8 knockout in rabbits recapitulates human congenital cataracts. Sci Rep, 6:22024.

Zhang X, Li W, Wu Y, Peng X, Lou B, Wang L, Liu M. 2017. Disruption of the sheep BMPR-IB gene by CRISPR/Cas9 in in vitro-produced embryos. Theriogenology, 91:163-172 e162.

Zhou X, Wang L, Du Y, Xie F, Li L, Liu Y, Liu C, Wang S, Zhang S, Huang X, Wang Y, Wei H. 2016. Efficient Generation of Gene-Modified Pigs Harboring Precise Orthologous Human Mutation via CRISPR/Cas9-Induced Homology-Directed Repair in Zygotes. Hum Mutat, 37:110-118. 